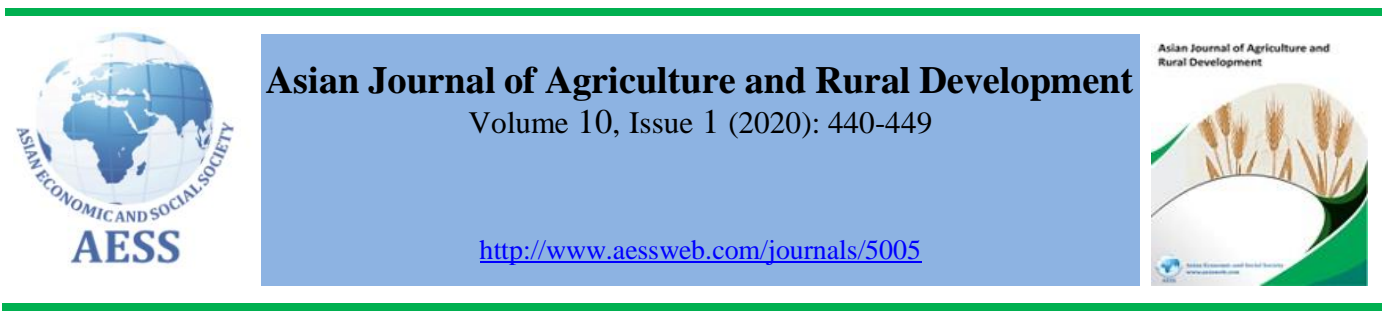

\title{
ECONOMETRIC ANALYSIS OF ACCEPTANCE OF SOIL AND WATER CONSERVATION TECHNIQUES IN THE SEMIARID REGION OF ZAGHOUAN (NORTH-EAST TUNISIA)
}

Anissa Gara
Mohamed Hammami $^{\mathrm{b}}$,
Sofiene Hammamic,
Mohamed Karim $^{\mathrm{c}}$ Aounallah',
Rabeb Elmouaddab $^{\mathrm{d}}$,
Mariem Nahdi $^{\mathrm{d}}$,
Lamia Laajili-Ghezal $^{\mathrm{d}}$

ARTICLE HISTORY:

Received: 25-Feb-2020

Accepted: 15-May-2020

Online Available: 20-Jun2020

\section{Keywords:}

Soil and water conservation, Farmers' adoption,

Tobit,

Probit,

Zaghouen,

Tunisia a National Agronomic Institute of Tunisia, Carthage University, Tunisia. AND Laboratory of Rural Economy at National Institute of Agronomic Research of Tunisia, Tunisia

${ }^{b}$ School of Higher Education in Agriculture of Mateur, Carthage University, Tunisia

${ }^{c}$ National Agronomic Institute of Tunisia, Carthage

University, Tunisia

${ }^{\mathrm{d}}$ School of Higher Education in Agriculture of

Mograne, Carthage University, Tunisia

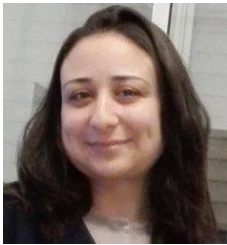

Corresponding author

- anissa.gara@gmail.com (Corresponding author)

ABSTRACT
The Tunisian government has established some strategies to face soil
erosion. In this research, we aim to study the perception of farmers
towards these conservation structures in terms of the acceptability of
installation of these amenities and terms of their maintenance. We try
to define the socio-economic variables that explain why some farmers
in the study area accept the installation of soil conservation facilities
while others do not and at what rate of maintenance. Therefore, we
used Tobit and Probit models to examine respectively the probability
of acceptance of conservations amenities (agreement of farmers that
conservation techniques be implemented on their lands) and the rate of
acceptance (allocation of land for maintained CTs). It comes out that
the factors affecting CTs acceptance are land size, animal husbandry,
irrigation from the lake, and land tenure.

Contribution/ Originality

This study contributes to the existing literature to identify the variables that affect farmers' perception of soil and water conservation facilities. It has investigated the factors that influence the rate of adoption and maintenance of these amenities. Using econometric analysis, this paper contributes to logical analysis about the social, technical and economical characteristics have influential roles in farmers' decisions related to the adoption of natural resources conservation technologies.

DOI: 10.18488/journal.1005/2020.10.1/1005.1.440.449

ISSN (P): 2304-1455/ISSN (E):2224-4433

How to cite: Anissa Gara, Mohamed Hammami, Sofiene Hammami, Mohamed Karim Aounallah, Rabeb Elmouaddab, Mariem Nahdi and Lamia Laajili-Ghezal (2020). Econometric analysis of acceptance of soil and water conservation techniques in the semiarid region of Zaghouan (NorthEast Tunisia). Asian Journal of Agriculture and Rural Development, 10(1), 440-449.

(C) 2020 Asian Economic and Social Society. All rights reserved. 


\section{INTRODUCTION}

Land degradation is a major challenge to effective agricultural production within dryland areas. This is especially true for countries such as Tunisia where land degradation has been of significant historical and contemporary concern (FAO, 2011).

Laajili and Stambouli (2019) affirm that the combined effects of global climate change and human activities on the degradation of natural resources generated significant economic and social costs related to the consequences of these modifications and the proposed solutions. To cope with this worrying situation, the integration of the environmental component to respond to agriculture and sustainable development is essential. Watershed management is an important component of sustainable development, integrating the physical and human potentials found in the watershed.

In Tunisia, it is essential to provide a more rational use of soil and water resources to meet the growing demand for water from the agricultural sector and limit the spread and the harmful effects of water erosion.

Indeed, Tunisia ranks among the Mediterranean countries most threatened by water erosion, in particular, semi-arid areas due to its geographic location in the Mediterranean basin, its rugged terrain, its fine soils poor in organic matter as well as its increasingly reduced plant cover. The aggressiveness of the climate generates significant losses of runoff water pouring into the seas (Melalih, 2012). Above and beyond, the population growth and the economic expansion of the country make the soil resource and even more, the water resource becomes more and more scarce requiring special management. The Department of Water and Soil Conservation affiliated to the Ministry of Agriculture has defined a national strategy aiming at collecting runoff water from small watersheds and developing stone benches and cords (Ministry of Agriculture Water Resources and Fisheries of Tunisia, 2014).

Soil and Water Conservation interventions were extensively implemented within the country since the 1950s, yet, their achievements have fallen below expectations (Roose et al., 2012).

This study was carried out in 2018 in the north-east of Tunisia and particularly in the governorate of Zaghouen at Oued Sbaihia watershed where the strategy for the conservation of natural resources has been applied since 2001 (CRDA of Zaghouen, 2019). It should also be noted that soil and water conservation techniques (SWCT) are installed by the Government at the request of the farmer. Except that some farmers maintain these facilities and others do not. This study aims to know whether the farmers -whose lands are managed by the conservation techniques (CTs) are satisfied with these conservation developments and are therefore favorable to this conservation strategy? Do they maintain these conservation structures? This could express their acceptance rates for these strategies.

It is in this context that this study provided knowledge on the social, economic, and technical factors affecting farmers' perception of conservation techniques. Previous research studies conducted in different areas of Tunisia indicate that different individual, economic, social, institutional and biophysical characteristics have influential roles in farmers' decisions related to the adoption of CT technologies (Bachta, 1995; Ouessar et al., 2006; He et al., 2007; Hall et al., 2009; König et al., 2012; Jara et al., 2013).

To achieve this objective, the econometric analysis was derived from cross-sectional data for a single production period. The Probit and Tobit models were estimated econometrically to assess respectively the acceptance probability (i.e., are farmers favorable towards conservation techniques or not) and the acceptance rate (i.e. do farmers maintain conservation techniques, this being expressed in terms of the area of land managed by conservation) by the farmers interviewed. Data 
were compiled using SPSS and analyzed using descriptive statistics, with econometric analyses undertaken to compare rates of adoption (and factors for adoption) between adopters and nonadopters (Dhehibi et al., 2018).

\section{METHODOLOGICAL FRAMEWORKS}

\subsection{Study area}

Zaghouan governorate is located on the eastern slope of Mount Zaghouan and dominates a vast agricultural plain (Figure 1). The Oued Sbaihia watershed is administratively attached to the Zaghouan delegation. This area is on the ridge of the Tell Atlas. The area is located in the semi-arid bioclimatic floor. The latitude to the right of the site is $36 \mathrm{G} 41$ 'while the longitude is 10G19'. The examination of the temperature data showed the variation of the temperatures recorded during the year 2018 , which vary between $37.8^{\circ} \mathrm{C}$ in July, and $6^{\circ} \mathrm{C}$ in February (FAO, 2011).
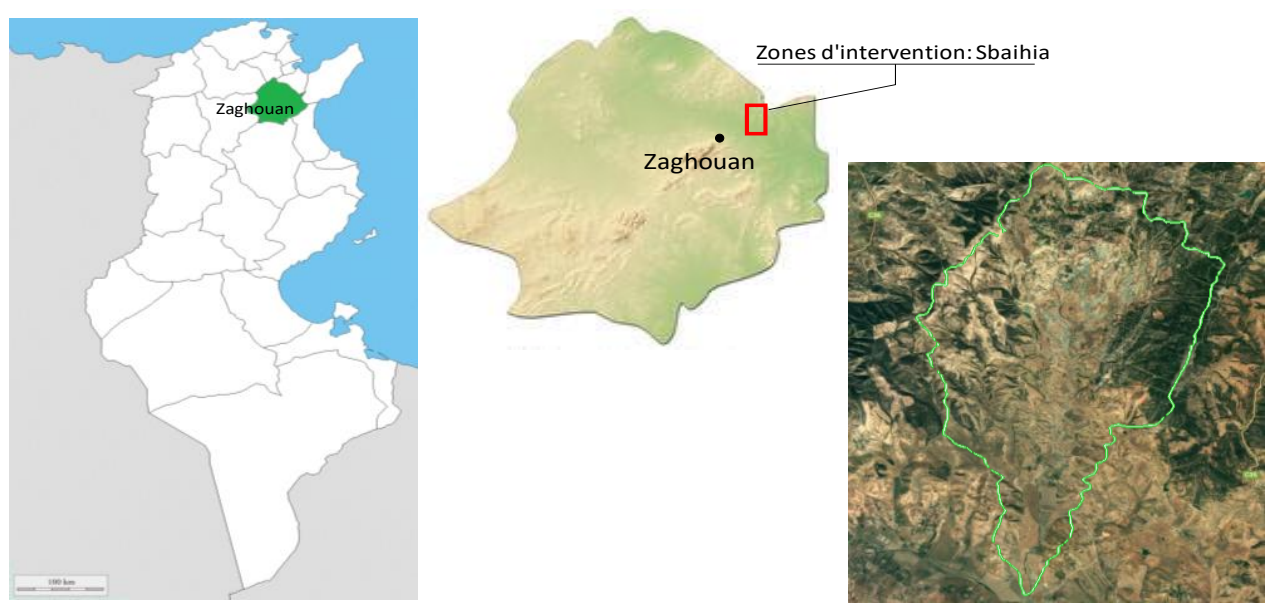

\section{Figure 1: The geographical location of the Oued Sbaihia watershed at the governorate of Zaghouen, Tunisia}

A visit of the whole Oued Sbaihya watershed was necessary to identify the two groups of farmers: 1) farmers who accept to adopt soil conservation techniques and maintain them 2) farmers who are reluctant towards these techniques.

A structured questionnaire has been designed, it contains 3 parts to collect general information on the farmer, his farm and his household, information on agricultural activities and information on CTs facilities (i.e. the presence or absence of the facilities and their current state, in other words, facilities maintained or damaged). The survey was designed as a simple random sample. A total of 134 usable questionnaires were recorded over a total of 206, representing a survey response rate of $65 \%$ which was suitable for this study, divided as follow: 56 farmers out of 134 accept to adopt soil conservation techniques and maintain them while 78 farmers out of 134 are reluctant towards these techniques.

The observed facilities are many, particularly: benches, gabion works, acacia, and Aleppo plantations for benches' consolidations, hill lakes, individual bowls, etc. (Ministry of Agriculture Water Resources and Fisheries of Tunisia, 2014). A detailed review of the local scientific and technical literature related to these interventions was recently compiled by Zucca et al. (2015). 


\subsection{Data analysis}

We used SPSS to code and edit data derived from questionnaires. Then, we used econometric methods such as Probit and Tobit models to precede at hypotheses tests (Landau and Everitt, 2004). We used the Probit model to examine variables influencing the agreement and acceptability of farmers towards soil and water conservation amenities. Also, we used the Tobit model to examine the variables that influence the level of acceptability of farmers (Gara, 2011).

Dhehibi et al. (2018) have researched to analyze the adoption of soil and water conservation techniques in the semiarid region of 'Sidi Bouzid' in the central part of Tunisia.

Probit and Tobit models are widely used to understand the main determinants of CT adoption which is a complicated process, similar to any other research on agricultural technology adoption, given the influence of a set of interrelated biophysical, socioeconomic, and institutional factors (Adesina and Chianu, 2002).

Many studies such as Tobin (1958), McDonald et al. (1980), Adesina and Chianu (2002), Menozzi et al. (2014), and Dhehibi et al. (2018) defined Probit and Tobit as econometrical models used to explain the relationship between dependant variable and independent variables.

The Probit model is used to understand the impact of some variables (independent variables) on the affected variable (dependant variable). This latter gives information by answering 'yes' or 'no'. Thus, it takes the value ' 1 ' when the answer is 'yes' and ' 0 ' when the answer is 'no', it is what we call a dummy variable (it takes zero or one). In our case, the question is: do the farmer is willing to adopt CT? The Answer is argued by the independent variables. That is to say, some independent variables explain why the farmer is favourable or not to adopt CT.

As for the Tobit model, it gives information about how much the dependant variable is affected by the independent variables. The rate of dependency takes a value truncated from ' 0 ' to ' 1 ' that is why it is a continuous value.

In what follows, we identify the dependant and independent variables for both Probit and Tobit models.

\subsubsection{Probit model}

To study the factors that affect CT agreement (rate of approval), a dummy variable, ' $A$ ' (meaning Agreement or acceptance of the farmer to adopt CT) was applied: it takes one if the household head $i$ of household $j$ accepts CTs to be installed at his farmland and zero otherwise, as described at the equation (1).

$$
\operatorname{Probit}(A=1)=f(F, L, P, C)
$$

Note that:

$F$ is a set of farmer characteristics (e.g. age, education, training, etc.)

$L$ is a set of land characteristics; (e.g. household size, land ownership, etc.)

$P$ is a set of the production system (e.g. size of farm, land ownership, number of cultures)

$C$ is a set of characteristics related to soil and water facilities (e.g. existence of benches and proximity to the lake)

That is to say, $A$ depends on $F, L, P$, and $C$. In other words, the acceptance of the farmer to adopt CT is affected by these variables: age, education, training, household size, land ownership, size of farm, land ownership, number of cultures, the existence of benches and proximity to the lake. 


\subsubsection{Tobit model}

In addition, we used Tobit model to express the intensity of agreement by measuring the proportion of land allocated for CTs that are maintained by farmers. This latter is a continuous variable truncated between zero and one and called ' $M$ ' to express the rate of maintenance of these conservation facilities by farmers (Equation 2).

$$
\text { Tobit }(0 \leq M \leq 1)=f(F, L, P, C)
$$

This equation (2) explains how much the independent variables (age, education, training, household size, land ownership, size of farm, land ownership, number of cultures, the existence of benches, and proximity to the lake) influence the probability of maintenance of CTs by farmers. Thus the intensity of adoption, expressed by the rate of maintenance, ' $\mathrm{M}$ ' is based on the characteristics sets related to farm, land, and production system $(\mathrm{F}, \mathrm{L}, \mathrm{P}, \mathrm{C})$.

\section{RESULTS AND DISCUSSION}

\subsection{Analyzed variables}

Tobit and Probit models were econometrically analyzed using some social economic and technical variables to apprehend farmers' perceptions (McDonald et al., 1980). Table 1 relates the different analyzed variables applied at Probit and Tobit models.

\section{Table 1: Description of the variables}

\begin{tabular}{|c|c|c|}
\hline Variable & Definition & Description \\
\hline $\mathrm{F}_{\mathrm{ij}}$ & $\begin{array}{l}1 \text { if household head } i \text { of household } j \text { is favourable towards CTs } 0 \\
\text { otherwise }\end{array}$ & Dummy \\
\hline $\mathrm{M}_{\mathrm{ij}}$ & $\begin{array}{l}\text { the proportion of land allocated for maintained CTs (truncated } \\
\text { between } 0 \text { and 1) }\end{array}$ & Continuous \\
\hline \multicolumn{3}{|c|}{ Farmer characteristics } \\
\hline Training & 1 if the farmer got some training, 0 otherwise & Dummy \\
\hline Educ & household head's years of schooling & Continuous \\
\hline Age & age of household heads (years) & Continuous \\
\hline \multicolumn{3}{|c|}{ Land characteristics } \\
\hline LO & Land ownership & Dummy \\
\hline Landsize & land size owned by the household head & Continuous \\
\hline Nbcult & Number of cultures & Continuous \\
\hline \multicolumn{3}{|c|}{ Production system } \\
\hline Animal & Number of animals & Continuous \\
\hline Olive & 1 if there is an olive tree, 0 otherwise & Dummy \\
\hline Cereal & 1 if there are cereals, 0 otherwise & Dummy \\
\hline \multicolumn{3}{|c|}{ Soil and water conservation practices } \\
\hline Water & Number of kilometers far away from the lake & Continuous \\
\hline
\end{tabular}

\subsection{Tested hypothesis}

Then, we assumed the following hypotheses that we tested:

$>$ Hypothesis 1: Exposure to formal education (measured in years of schooling) increases a household head's awareness about conservation strategy and erosion risks and hence education increases the probability of rate and intensity of acceptance.

$>$ Hypothesis 2: Farmer who has purchased his land is more likely to adopt conservation techniques (CTs) and allocate more land under CTs to raise farm productivity rather than an heir.

$>$ Hypothesis 3: Proximity to the lake increases the likelihood that a household head $i$ of household $j$ accepts CTs farming system. 
> Hypothesis 4: The marginal probability that a farmer accepts CTs farming system increases with a unit increase in farmland's size.

$>$ Hypothesis 5: Animal husbandry farming influences the probability of acceptance of SWC in a negative way.

\subsection{Factors affecting the acceptance of CTs}

Tables 2 and 3 offer detailed results about Probit and Tobit models (see Appendix).

To test hypotheses 1 to 5, Probit and Tobit's models were econometrically estimated for a rate of acceptance (i.e., agreement of conservation techniques, CTs) and intensity of acceptance (i.e., allocation of land for maintained CTs). The estimation coefficients inform about the marginal effects of an explanatory variable on the expected value (mean proportion) of the dependent variable $A$ and changes in the rate of acceptance for a unit change of an independent variable among farmers who are favourable towards SWCT for dependent variable $M$. The LR $\operatorname{chi}^{2}(14)$ statistic represents a test of the null hypothesis that the expected values of the regression coefficients are equal to each other and that they equal zero.

That is to say, this statistic checks if the pseudo $R^{2}$ proportion of variance in the dependent variable analyzed by the predictors is zero. In the case where the null hypothesis was correct, then there is no regression relationship between the dependent variable and the predictor variables.

The results show that the predictor variables for both Probit and Tobit models are not all equal to each other and could be used to predict the dependent variable as indicated by a big LR chi $^{2}(14)$ and a small significance level $(p<0.000)$. That is, $\mathrm{LR} \mathrm{chi}^{2}(14)=128.62$ for Probit regression and LR $\operatorname{chi}^{2}(14)=210.23$ for Tobit regression. So the null hypothesis can be rejected. Hence we conclude that at least one of the independent variables is related to the dependent variables $A$ and $M$.

It comes out that the factors affecting CTs acceptance are education, land size, animal husbandry, irrigation from the lake, and land tenure. These variables also have a positive and significant effect on the rate of acceptance.

\subsubsection{Farmers education and experiences}

An increase in one year of schooling increases the probability of CTs adoption by $1.7 \%$ and increases the surface of maintained facilities of 0.023 ha. This supports the first hypothesis. Education is often argued as a variable that influences rates of adoption (Alcon et al., 2011). As well, sharing experiences between farmers would be an elemental solution to encourage farmers to adopt and implement CTs by themselves in case of deficiency or non-existence of governmental assistance. Membership of farmers within Community Based Organization (CBO) and/or farmers' cooperatives to which they belong, in addition to the intensity of farmers' interaction with extension services, are considered as proxies of farmers' participation in the learning process and knowledge related to CTs (Dhehibi et al., 2018).

It is important as well to improve market transactions to help the small farmer to trade their products. The existence of efficient capital market institutions especially devoted to smallholders, including the wide variety of micro-finance schemes, could help small farmers to overcome some of the financial constraints. Moreover, subsidies and related legal frameworks can also encourage farmers to convert to new production systems (Karaa et al., 2008; Alcon et al., 2011).

\subsubsection{Land tenure}

Furthermore, being a purchaser of land increases the probability of CTs adoption by $19 \%$. Hence it supports hypotheses 2 . The land tenure variable has also a positive and significant effect on the level of maintaining CTs. One of the obstacles to embracing conservation development is land 
tenure insecurity. Land tenure rights are prone to unpredictable changes, besides land ownership title is unclear. These two reasons make the farmers not certain about the future, thus they are not sensible and concerned about soil condition and are not aware of erosion problems. These farmers think about short term profit and might be reluctant to sustainable land management. Most of the farmers still feel uncertain and ambivalent about land ownership. Thus, there is a great necessity to clarify policies about land ownership. In view of that Lovo (2016) says "tenure insecurity can have important consequences for the conservation of natural resources, sources of insecurity have a negative effect on soil conservation investments".

\subsubsection{Lake proximity}

On the other hand, the distance between the farmland and the lake had negative and significant results showing that increasing one kilometer from the lake reduced the probability of accepting CTs by $21.5 \%$, thus supporting hypothesis 3. Correspondingly, one kilometer far away from the lake induces a decrease of 0.4 ha of land equipped with maintained CTs. Results showed that only conservation facilities that have direct utility headed for the population (water tank, irrigation, watering livestock) are more likely to have a longer lifespan. Because they would more likely to be maintained and protected against any form of degradation (theft of gabion, stones, etc.) Farmers within lake neighbouring take advantage of lake water and thus they think that this kind of conservation structure is profitable (Baumgart et al., 2012).

This is an obvious finding especially in an arid zone where water is in short supply such in many areas in Tunisia (Laajili-Ghezal et al., 2019).

\subsubsection{Farmland size}

Farmland size was highly statistically significant $(p<0.001)$ meaning that a one-hectare increase in farmland size increases the probability of acceptance of CTs by $24 \%$. Moreover, one hectare increase in a useful agricultural area increases land allocation under maintained CTs (level of maintenance) by 0.05 ha, hence supporting hypothesis 4 . The conservation structures occupy some part of the land and consequently, this reduces the effective cultivated area. Therefore, land spaceconsuming according to the small land size makes it not worthy to install the CT.

Furthermore, land fragmentation, land scarcity problem and increase distance between different plots of the same farm property make difficult to implementation of the conservation facilities in the small lands. In fact, according to farmers' statement, the reasons for decreased crop yield are the fragmentation issue due to population pressure and land inheritance from one hand, and to the reduction of soil fertility due to degradation and frequent drought on the other hand. Land fragmentation induces more time-consuming for the carriage of inputs, equipment, and yield products to move from a plot to another.

Also, land in this area has harsh topography which confines the implementation of soil and water conservation techniques. Moreover, conservation structures collected fertile soils that could be used to increase short-run production by dismantling the structures and spreading out the soil collected there. Also, soil and water conservation techniques could harbour rats that may damage the crops, and water ponds could attract mosquitos and insects. In addition Dhehibi et al. (2018) suggest the promotion of cooperative work strategies among farmers who lack resources to perform conservation technologies and the encouragement of information and experience exchange between farmers who have extensive experience with conservation technologies and those without experience.

\subsubsection{Animal husbandry}

As expected, coefficients of livestock farming in acceptance and maintenance were negatively and statistically significant, thereby it supports hypothesis 4 . One unit increase in animal husbandry reduces the probability of acceptance of farmers by $15 \%$ and reduces the rate of maintaining the 
CTs by 0.031 ha. This could be argued by the fact that livestock damages the benches while grazing in the land. In addition, gabions and dry stone cords make it difficult for animals to access them. This explains the unfavorable perception of certain farmers-breeders towards the CTs. Dhehibi et al. (2018) conclude that this negative trend has significant implications for adoption. Overgrazing is of significant concern in the study area. The observations that livestock producers would appear to be less keen to adopt conservation practices are consistent with the hypothesis that conservation technologies and conventional livestock rearing practices may not necessarily be compatible".

\section{CONCLUSION}

Adoption rates of water and soil conservation techniques can be ascribed to many reasons such as educational, financial, and technical factors that should be considered as a priority, especially in the context of the environmentally sensitive areas of Tunisia. The Tunisian government should provide sufficient training and extension programmes to farmers. Implementing these recommendations can improve the contribution of conservation farming to household income, poverty alleviation and hence render a positive impact on the overall agricultural sector development. To increase the approval rate of the farmers towards CTs, the participatory approach is the most suitable and proper solution and should be improved and evenly spread among farmers.

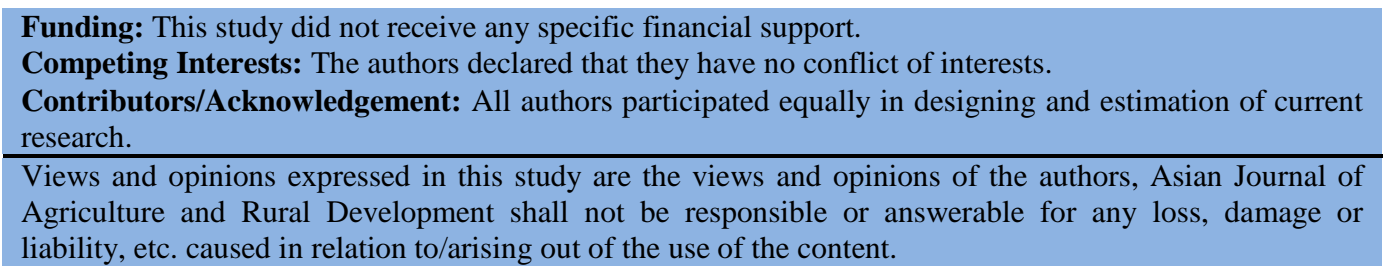

\section{References}

Adesina, A. A., \& Chianu, J. (2002). Determinants of farmers' adoption and adaptation of alley farming technology in Nigeria. Agroforestry Systems, 55, 99-112.

Alcon, F., De Miguel, M. D., \& Burton, M. (2011). Duration analysis of adoption of drip irrigation technology in southeastern Spain. Technological Forecasting \& Social Change, 78, 9911001.

Bachta, M. S. (1995). Water and soil conservation (CES) in Tunisia. Public intervention and peasant strategies: an economic perspective. In: Zekri S., Laajimi A. (eds.), Agriculture, sustainability and environment. Mediterranean Options Notebooks, CIHEAM, Zaragoza, 9, $35-47$.

Baumgart, G. A., Stalker, P. L., \& Floress, K. (2012). Why farmers adopt best management practice in the United States: A meta-analysis of the adoption literature. Journal of Environmental Management, 96, 17-25.

CRDA of Zaghouen (2019). Zaghouen regional agricultural development commission, CES District. Variation of the new strategy in strategic directions, Zaghouan.

Dhehibi, B., Zucca, C., Frija, A., \& Kassam, S. N. (2018). Biophysical and econometric analysis of adoption of soil and water conservation techniques in the semiarid region of Sidi Bouzid (Central Tunisia). New Medit Journal, 2, 15-28. doi.org/10.30682/nm1802b.

FAO (2011). The state of the world's land and water resources for food and agriculture (SOLAW) Managing Systems at Risk. Food and Agriculture Organization of the United Nations, Rome, Italy. London: Earthscan.

Gara, A. (2011). Assesment of soil conservation impact on rural development in central Ethiopia. Ph.D. Thesis dissertation at Tokyo university of agriculture, Japan.

Hall, T. J., Dennis, J. H., Lopez, R. G., Marshall, M. I. (2009). Factors affecting growers' willingness to adopt sustainable floriculture practices. Horticulture Science, 44, 1346-1351. 
He, X. F., Cao, H., \& Li, F. M. (2007). Econometric analysis of the determinants of adoption of rainwater harvesting and supplementary irrigation technology (RHSIT) in the semiarid Loess Plateau of China. Agricultural Water Management, 89, 243-250.

Jara, R. R., Bravo, U. B. E., Engler, A., \& Diaz, J. (2013). An analysis of the joint adoption of water conservation and soil conservation in Central Chile. Land Use Policy, 32, 292-301.

Karaa, E., Ribaudob, M., \& Johansson, R. C. (2008). On how environmental stringency influences adoption of best management practices in agriculture. Journal of Environmental Management, 88, 1530-1537.

König, H. J., Sghaier, M., Schuler, J., \& Abdeladhim, M. L. (2012). Participatory impact assessment of soil and water conservation scenarios in Oum Zessar watershed, Tunisia. Journal of Environmental Management, 50, 153-165.

Laajili, G. L., \& Stambouli, T. (2019). Tools for the sustainable management of natural resources in Tunisia. 65 pages. Editions Universitaires Européennes.

Landau, S., \& Everitt, B. S. (2004). A handbook of statistical analyses using SPSS. Chapman and Hall/CRC Press LLC.

Lovo, S. (2016). Tenure insecurity and investment in soil conservation. evidence from Malawi. Journal of World Development, 78, 219-229. doi.org/10.1016/j.worlddev.2015.10.023.

McDonald, J. F., \& Moffit, R. A. (1980). The uses of Tobit analysis. The Review of Economics and Statistics, 62, 318-321.

Melalih, A. (2012). Analysis of water and soil conservation techniques in the arid zone of the Ain Sefra watershed.University of Abou-bekr Belkaid-Tlemcen, Algeria, 143p.

Menozzi, D., Fiorvanzi, M., \& Donati, M. (2014). Farmer's motivation to adopt sustainable agricultural practices. BAE Bio based and Applied Economics, 4(2), 125-147.

Ministry of Agriculture, Water Resources and Fisheries of Tunisia (2014). Water sector review in Tunisia. Planning and hydraulic balances office, Tunisia.

Ouessar, M., Yahyaoui, H., Belgacem, A.O., \& Boufalgha M. (2006). Arrangements and techniques to combat desertification: Inventory and assessment. In: Genin D., Guillaume H., Ouessar M., Belgacem A.O., Romagny B., Sghaier M., Taamallah H. (eds), Between desertification and development: the Tunisian Jeffara. CERES, Tunis, 147-161.

Roose, E., Sabir, M., Arabi, M., Boutkhil, M., \& Mazour, M. (2012). Sixty years of cooperative research on water erosion and erosion control in the Maghreb. Physical Geography and Environment, 6, 43-69.

Tobin, J. (1958). Estimation of Relationships for Limited Dependent Variables. Econometrica, 31, 24-36.

Zucca, C., Hermassi, T., Ouessar, M., \& Frija, A. (2015). Impacts of soil and water conservation techniques in Tunisia. Inventory of research works and studies. ICARDA, CGIAR. Technical report, 45 p. Tunisia. 


\section{Appendix}

Table 2: Factors affecting the rate of adoption in Conservation Techniques (CTs)

Probit regression, reporting marginal effects $\quad$ Number of obs $=134$

$$
\begin{aligned}
\text { LR }_{\text {chi }}{ }^{2}(14) & =128.62 \\
\text { Prob }>\text { chi }^{2} & =0.0000
\end{aligned}
$$

Log likelihood $=-11.805232$

Pseudo $\mathrm{R}^{2}=0.8554$

\begin{tabular}{lccccccc}
\hline Variable & $\mathbf{F}$ & $\mathbf{d F} / \mathbf{d x a}$ & Std. Err. & $\mathbf{z}$ & $\mathbf{P}>|\mathbf{z}|$ & $\mathbf{x}-\mathbf{b a r}$ & [95\% C.I.] \\
\hline Landsize & 0.2427 & 0.0125 & 1.7700 & $0.000^{* * *}$ & 26.0508 & -0.0033 & 0.0477 \\
Educhh & 0.0171 & 0.0660 & 0.2200 & $0.033^{* *}$ & 1.6405 & -0.1353 & 0.1434 \\
Age & 0.0071 & 0.0100 & 0.6800 & 0.4980 & 47.7750 & -0.0126 & 0.0278 \\
Olive & 0.0318 & 0.0862 & 0.3600 & $0.010^{*}$ & 3.5576 & -0.1376 & 0.2008 \\
Animal & -0.1500 & 0.0000 & -0.6800 & $0.043^{* *}$ & 4849.4000 & -0.0001 & 0.0001 \\
Nbcult & 0.0121 & 0.0011 & 0.7900 & 0.4240 & 1730.8300 & -0.0001 & 0.0003 \\
Training & 0.1026 & 0.3848 & 0.2500 & 0.7870 & 0.8000 & -0.6515 & 0.8567 \\
Cereals & -0.0426 & 0.0608 & -0.7100 & 0.4900 & 7.0708 & -0.1618 & 0.0776 \\
Ltenure & 0.1909 & 0.2319 & 1.4100 & $0.001^{* * *}$ & 0.4417 & -0.0837 & 0.8275 \\
Lakedis & -0.2152 & 0.0001 & -2.3700 & $0.018^{* *}$ & 6885.9400 & -1.0005 & \\
Obs. P & 0.531658 & & & & & & \\
Pred. P & 0.6163956 (at x-bar) & & & & & \\
\hline
\end{tabular}

(a) $\mathrm{dF} / \mathrm{dx}$ is for discrete change of dummy variable from 0 to 1

$\mathrm{Z}$ and $\mathrm{P}>|\mathrm{z}|$ correspond to the test of the underlying coefficient being 0

Note: $*, * *$ and $* * *$ indicate statistical significance at $10 \%, 5 \%$, and $1 \%$ levels respectively

Table 3: Determinants of the intensity of adoption in Conservation Techniques

Tobit regression $\quad$ Number of obs $=134$

$$
\begin{aligned}
\mathrm{LR} \text { chi }^{2}(14) & =210.23 \\
\text { Prob }>\text { chi }^{2} & =0.000
\end{aligned}
$$

Log likelihood $=54.769 \quad$ Pseudo $\mathrm{R}^{2}=0.834$

\begin{tabular}{lcccccc}
\hline Variable & $\mathbf{M}$ & Coef. & Std. Err. & $\mathbf{t}$ & $\mathbf{P}>|\mathbf{t}|$ & [95\% C. I.] \\
\hline Landsize & 0.05007 & 0.0086 & 3.9700 & $0.000^{* * *}$ & 0.0171 & 0.0512 \\
Edu & 0.02392 & 0.0012 & 3.1500 & $0.002^{* *}$ & 0.0014 & 0.0064 \\
Agehh & 0.00016 & 0.0011 & 0.1200 & 0.9070 & -0.0021 & 0.0024 \\
Olive & 0.00257 & 0.0026 & 1.0300 & 0.3060 & -0.0024 & 0.0077 \\
Animal & -0.03180 & 0.0059 & -5.4100 & $0.000^{* * *}$ & -0.0434 & -0.0202 \\
Nbcult & 0.00769 & 0.0055 & -1.4000 & 0.1640 & -0.0185 & 0.0032 \\
Training & 0.00001 & 0.0001 & 1.3400 & 0.1820 & -0.0001 & 0.0000 \\
Cereal & -0.02572 & 0.0340 & -0.7600 & 0.4510 & -0.0931 & 0.0417 \\
Ltenure & 0.03023 & 0.0448 & -0.6700 & $0.001^{* * *}$ & -0.1190 & 0.0586 \\
Lakedis & -0.04005 & 0.0000 & -9.9700 & $0.000^{* * *}$ & -0.0001 & 0.0000 \\
Sigma & 0.15112 & 0.00989 & 0.12571 & 0.16713 & & \\
\hline
\end{tabular}

Obs. summary: 7 left-censored observations at $\mathrm{M}<=0$

104 uncensored observations

0 right-censored observations

Note: $*, * *$ and $* * *$ indicate statistical significance at $10 \%, 5 \%$, and $1 \%$ levels respectively 